\title{
Body Hair : A Cultural Politics Approach
}

\author{
Mao Jia \\ THE UNIVERSITY OF NOTTINGHAM, NINGBO, CHINA
}

maojia123261@gmail.com

Keywords: Gender study, feminism, Body hair, Female body, Control society.

\begin{abstract}
Hair, as one of the most obvious character of biology, has been divided in two categories: the hair on the top of your hair and body hair includes mustache, armpit hair and the hair covers on your leg or chest. Generally, when mass communities talk about the hair on the head, the contexts are always referring to admired and valued [11]. Further more, there are endless poems and songs to express people's praise of the charming hair, which allowed to be exposed in the public areas. But on the other hand, body hair is being treated like a taboo and animal-like, similar with menstruation, both belong to the impolite topic and cannot be permit to mention on the table, although hair shave is strongly normative across contemporary social cultures. Moreover, the body hair, especially for the woman, is endowed with a signal that involved with: shame, dirty and disgust, the closer women come to talking bout body hair as a verbalization that belongs in the private realm. These ideologies and stereotypes of body hair were gradually shaped during the construction of action culture, As Jeff [16] suggested that, human body can be regarded as a sensation, not only biology, and it also be understood, analyzed and came out means by culture. So, as a unique but prejudiced example, body hair contains various feminisms and poststructuralist theories, I will try to research the philosophies of several gorgeous researcher: Foucault, Judith Butler, Simone de Beauvoir... to found the essential power which behind this biological foundation in the theories of gender and feminism, and the how power works among these constructions progress of hair significance in visual culture, furthermore, the body under the lens how to shape the public stereotypes.

In the first place, Rather than hair be regarded as part of "nature" body and unmarked, there can be described various theories about gender, sexuality and feminism. Also, body hair carried its unique visual and discourse identities, such as Foucault [8] indicates body as a primary site where social relations operate and be used to explored ideologies of power so people can be influenced by the idea of community and be treated due to different politics.
\end{abstract}

"To shave or not to shave?" this question was raised by Arizona State University professor Breanne Fahs [6] in her class and research since 2008. The students can get extra marks if they willing participate this 10weeks experiment, which encouraged female students to hold the underarms and legs hair. For the boys, they need to shave all of the body hair under the neck and take note for their self-experience and others response. Cause hair removal has already a part of acquiescently routine, mostly female experimenters notes they felt disgusted when they saw themselves in the mirrors, some of them thought they looks still very dirty even after shower, it is not the filth of body, but a impurity of mind. In other words, it's a kind of negative self-recognized. It is refers to the argument of Descartes [10] and his famous study of self-identity, self mind is separate from your own body, which means "body is something your self has to adjust to or cope with"(Emily, [10]), woman can experience strongly uncomfortable and passive emotions for their body they need to "cope with". Another reason why the girl felt horrible for herself, that is the human body can send back the signals. The body sends the signal to the body that accustomed of hairless, although the experiment accept the rule already, the subconscious hairless mind are not used of it. Out of the focuses on gender, culture and sexual came a attention on the body itself. For instance, Around 1980s, people began identifying themselves and each other as "marked persons"(Pitts, [15]) what they shared is their personal experience and emotions, and their body is the site of exploration, the place to exploring identity and personal emotions. So, similarly found that women feel for body hair is the most instinctive feeling of their self-modification, this feeling is 
doesn't matter with medical religion, or body to be seen. May be just the human-bings, as the most senior animal, the most direct experience of body hair when they saw that. But "No one is an island" (Merton, [12]), we all staying diversified and liquid relationships now, Self-perception of the standard also influenced by these relationships and the environment. Such as interpersonal communication and discourse, evaluate others and your passive acceptance of your identity and category. "Self-recognition" was be contested and re-shaped by social etiquette and judgment. Therefore, the sign of the female identity decided the generally femininity, and woman's body is not controlled by themselves actually since the body surrounded by human civilization.

"The dominant sociocultural meanings in the West construct desirable female bodies as slim and smooth (hair-free) and male bodies as toned "(Grogan, [9]). It should be highlighted and further discussed that "why the person who doesn't shave the body hair should be regarded as the dirty and shameless is girl?" Male don't feel any awkward about their body hair, even in this experiment, the boy was not request to hold their extra hair same with the girls, but needs to shave them. So, the body hair maybe contains sign of the gender distinction. For example, Karin [11] was points out, different with the social role of "body weight", women's body hair prefer plays an important part of femininity. A woman who is overweight can be tagged with stereotypes, such as unattractive or undesirable. But at least, she was be still be treated and discussed in the "woman" area, and issue of body weight is also become an aspect of "femininity'. On the contrast, the "hairy women" are lamentable in being like male, or masculine. It seems like the character of feminine only promise woman to exposed the hair on the top of head. One more excessive instance is the bearded women character in the teleplay [American horror story: freak show], her identity is "man-like" and "freak". "They are not viewed as particularly feminine, however, and thus take on negative connotations here Braman [1] states that. Some girl students during the Breanne's test duration had arguments with their boyfriend, because the boys cannot accept the changes that happened in their girlfriend. To be a short conclude, what makes people "recognizable" man or woman? The awareness of male and female in our mass culture are inescapable controlled by the idea of " nature" or "culture", on the other hand, what makes the different between "sex "and "gender".

Besides the themes of gender reorganization and attractive body. Body hair is also means a kind of "choice" happens on "body". (Fahs, [5] ) the topic of "How to deal with your body" is seems like a totally private matter, But why mostly part of female admitted the normalization process happened in their ideology area? It's not they do not want to resistance, "You cannot escape a prison if you do not know you are in one" (Deleuze, [4] ) But things may be worse than that. Deleuze asks "How are the masses made to desire their own enslavement, and to fight for it as passionately as if it was their own freedom?"

Female willing be defined maybe due to these profoundly history imbalanced gender roles. One part of female regard the "shave hair" as self-willing, they don't feeling any composed or dominated for them, Fahs [6] notes that I think it's a choice that I make a requirement,', whereas Keisha (a 34year-old American woman) states, "It's a choice, but if it gets out of hand it should be a requirement to shave, especially if you have body odor. It should be required!" So, although the women themselves insist that in the performance of their own power, and that depends entirely on whether the individual wishes of hair removal, but they never cover up when they do not discuss those gross and disgusting woman disgusted tone. The subconscious precepts of body ideology are what Foucault valued and emphasized.

Behind the suffering under the self- identify and gender confused, the culture pressure of the woman cause they still couldn't choose and control their body as they willing. This kind of dominated was not expressed by violence or force any more, but hidden in the invisible social discipline. In the second wave feminism, Simone [2] states that "One is nor born, but rather becomes, a women". She explains that woman were not fully human because actually female was defined by male, even in the new openly capitalism society. She also claimed that gender is different with sex, cause in the essentialism feminism, there has one purer boundary between body and sex. Sex is the identity, which everyone owned since birth. But gender is different, the man is the subject, he is absolute, and she is the object, and the other. In the terms of gender, man is 
essential and has transcendent means for woman. One more specifically example, girls hold their body hair during the experiment period is just once on the body's resistance, but this behavior in itself threats to anyone? This means that women using the power of the male exclusively, stated by Fahs [6] , and shaving body hair is a symbol of obedience. Like monks need Bald. The women obey to the rules established by masculinity. For instance, whether female or male participants, the evaluation of attention from other men are far beyond women. Women care about boyfriends, fathers, male friends, male colleagues and even strangers on the street a man's perspective. Men are actually concerned about a group of people is almost the same: their male friends, brother, father, and so on. It is enough to show that the male human body has greater voice. In the same way, the normalization of Women's Body Hair Removal is women's compromise of their gender;men control standard-setting powers. In the relationship between gender and the body, has been a surge of patriarchal power lurks. Pursing this further, in the other body modifications, for example, the pursuit of contemporary women: long legs, white or tan, plastic surgery. These are designed to meet the aesthetic standards of men, which is the second and third waves generation of feminists initiated against reason.

In postmodern society, body is understood as political and social, and diverse realms of power relationship inscribed body modification. In the third wave feminism, which impacted by Foucault and Judith's poststructuralist theories. The body seems like escaped from the discussion of essentialism womanhood, and have development from the former Beauvoir's announcement, besides the power analysis between the body and gender, body and feminism. Additionally, Foucault pay more attention to the relationship between the body and the discourse, he thinks the relationship is more invisible and ubiquitous.

Since "remove hair" came be a considered gender sign, the visual of hairless body is become a normative visual pleasure. Similar with tan, slim body and long leg. The consequence is, customer can find the shampoo and hair oil advertisement on the magazines easily; the models are always having smooth skin, hairless body and sexy bodily form. And stranger scene what we can see in the images is, even in the posters of some hair remove products, the body under the lens is already without any hair, the foam on the skin was used to remove nothing. We can never see the sexy super model in the Victoria's secret (American famous underwear brand) fashion show with the hair-covered body. Because body hair in people's discourse never have any relationship with aesthetics, and not be favored by businessmen. This visual convention is a kind of bondage for women actually. If the body is understood from ideology to discourse, then the body can be shaped and re-create in an area of social knowledge. In the contemporary society, masculinity still control the discourse hegemony in the mass media and popular visual culture, at same time, they are also set limits on the way populace's aesthetic think, treat and judge to the female body. The most directly way to explore the idea is gaze. In Mulvey's "Visual pleasure and narrative cinema"[13], the cinema and some other forms of TV programs, can offers various different pleasures. Freud [7] defined the desire of "Scopophilia" as an instinctive longing for femininity, within this theoretical range, associated scopophilia with talking women as object, categorizing and defining them into the controlling and curious gaze. The images under the lens is particular responsible for the perpetuation of the normalization of the hairless femininity. In the famous American sitcom "Friends", the heroine and her roommate discussed to wax their legs, but there do not have any lenses for the legs covered hairs, and they still like to act painful when they ripped the wax paper off. But the more interesting fact is, when these girls try to remove hair even suffering pain, it is one kind of action in order to catering the public pleasure, It should be sounds like a very frustrating thing, cause this behavior is means of obey to the discipline. But on the contrary, these women are absolutely very pleased and excited because they have a favorite object of smooth skin. It sounds cruel and lamentably, but actually it is a invisible discipline in the visuality, without punishment and violence, female was be analyzed in to various site, hairless skin is just a tip of the iceberg. Based on screen, the female body and appearance to change what motivated by patriarchal oppression and control, as well as capitalism "discipline" and make the dynamic response, in order to obtain the male "Lovejoy" in line with modern consumer society aesthetic rules. Lesnik- 
Oberstein [11] also tried to search the origins of the hairless body obsession in the terms of visual. She suggested that since the descriptions in myth, already has a traditional link of body hair and evil, danger; ugliness combined with hirsute witches,and unkempt hair means insane.

The last point worth to discussed is, besides the visual of female hairless body, for the man, their body hair always has another obviously different discourse with woman. In many film images that described gay, always their body is after shaved. Cause mostly male does not care about their haircovered body in their daily life, except shave beard. In the Fahs experiment, At the beginning, the boys seemed very relaxed, most of them began to think that it did not matter, they think (participating in the experiment) would not get any response." The results are surprising, someone will find fault with them, ridicule them "woman-like" s body, or be judged as a homosexual. Butler [3] states is discourse judgment of male or female is a kind of heterosexual hegemony. The subject of homosexual is constituted through the force of abjection, the body hair, as a signs of masculinity, was considered as exclusion of female heterosexual, but for the male, the situation is oppositely. There is the combination of gaze and gender, visual and heterosexual hegemony. Since "hairless" tagged with gay, it is easier for cinema and media industry to show and build these characters, cause the body hair was be identified by the normalization aesthetics on the screen. On the contrary, these role shaping deepening of the audience for the gay community prejudice and stereotype further.

In the final analysis, this paper begins with the Fahs professor's experiment about her student body hair, at the different stages of this bold test and different aspects. Firstly, tried to discussed several relationships between body hair and gender, feminism; Gender is different with sex, it is a identity which defined by policing and m.ral regulation rather than "nature" body. And then topic move to the hairless skin with visual, gaze, and concludes that the gaze, visual subjects are all encourage the active male subject and passive female object; And final talk about the body and heterosexual hegemony is focus on the discipline and normalization of male and female body hair. All of these opinions are purpose to making the "body hair" break the identity of "taboo", but a common culture approach relative to all of us. Various postmodern or feminism theories used to evidence how human-bing be reshaped and changed by power and discourse invisibly, even be the willing slaves. But, when these discussion sum up together, It is not hard be able to find a common ground: the main powers still in the hands of masculinity, even after three waves of feminisms. But, that is not means female cannot get rid of the yoke, to rebel against the discipline. Actually, by challenging the taboo of body, even just open up the ways to negotiating this culture approach, can make advantage of waking up more personal and political awareness.

\section{References}

[1] Basow, S. and Braman, A. (1998). WOMEN AND BODY HAIR. Psychology of Women Quarterly, 22(4), pp.637-645.

[2] Beauvoir, S. (1953). The second sex. New York: Knopf.

[3] Butler, J. (1993). Bodies that matter. New York: Routledge.

[4] Deleuze, G. and Boundas, C. (1993). The Deleuze reader. New York: Columbia University Press.

[5] Fahs, B. (2012). Breaking body hair boundaries: Classroom exercises for challenging social constructions of the body and sexuality. Feminism \& Psychology, 22, 482-506.

[6] Fahs, B. (2013). Shaving it all off: Examining social norms of body hair among college men in a women's studies course. Women's Studies: An Inter-disciplinary Journal, 42, 559-577.

[7] Freud, S. and Strachey, J. (1966). The psychopathology of everyday life. New York: Norton.

[8] Foucault, M. (1977). Discipline and punish. New York: Pantheon Books. 
[9] Grogan S. (2008). Body image: Understanding body dissatisfaction in men, women \& children. London, England: Routledge.

[10] Hepworth, M. and Martin, E. (1987). The Woman in the Body: A Cultural Analysis of Reproduction. The British Journal of Sociology, 42(1), p.160.

[11] Lesnik-Oberstein, K. (2006). The last taboo. Manchester: Manchester University Press.

[12] Merton, T. (2005). No man is an island. Shambhala Publications.

[13] Mulvey, L. (1975). Visual Pleasure and Narrative Cinema. Screen, 16(3), pp.6-18.

[14] Pednaud, J. (2012). GRACE GILBERT - The Bearded Lady - The Human Marvels Freaks. [online] Circus Freaks and Human Oddites. Available at: http://www.thehumanmarvels.com/gracegilbert-the-bearded-lady/ [Accessed 11 Dec. 2014].

[15] Pitts-Taylor, V. (2003). In the flesh. New York: Palgrave Macmillan.

[16] Rhizome.org, (2013). The Body as an Object of Interference: Q+A with Jeff Kolar.

[online] Available at: http://rhizome.org/editorial/2013/feb/15/q-jeff-kolar/ [Accessed 11 Dec. 2014].

[17] Toerien, M. and Wilkinson, S. (2003). Gender and body hair: constructing the feminine woman.Women's Studies International Forum, 26(4), pp.333-344. 